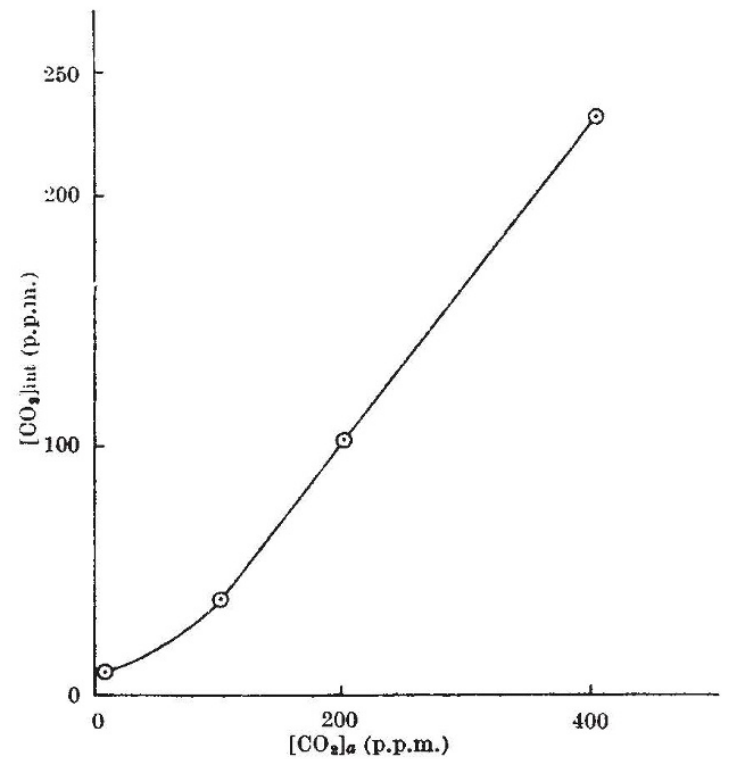

Fig. 1. Concentration of carbon dioxide at the internal cell surface, $\left[\mathrm{CO}_{2}\right]$ int, as a function of the concentration in the atmosphere, $\left[\mathrm{CO}_{2}\right]_{a}$

air. The $\left[\mathrm{H}_{2} \mathrm{O}\right]_{\text {int }}$ was assumed equal to the saturation vapour concentration at leaf temperature ${ }^{3}$.

The illumination on a horizontal plane was $10,000 \mathrm{ft}$. candles at the top and 6,500 $\mathrm{ft}$.-candles at the bottom of the corn shoots. The concentration of carbon dioxide in the atmosphere, $\left[\mathrm{CO}_{2}\right] a$, was maintained at $8,100,200$ and 400 p.p.m. and $T$ and $P$ were measured at each concentration. $\left[\mathrm{CO}_{2}\right]_{\text {int }}$ was calculated and is shown in Fig. 1. Each point in Fig. 1 was calculated from the average of six consecutive 10 -min determinations of $T$ and $P$ after a steady-state was reached.

As expected, the concentration of carbon dioxide inside the leaf increased as the concentration in the atmosphere increased. However, the increase in $\left[\mathrm{CO}_{2}\right]$ int was not directly proportional with increasing $\left[\mathrm{CO}_{2}\right]_{a}$ because stomatal resistance changed with changes in carbon dioxide concentration. Measurements of the stomatal apertures were taken by means of silicone rubber replicas ${ }^{4}$. At 8 p.p.m., 100 per cent of the stomata had an aperture-width greater than $1 \mu$. At 100 p.p.m., 70 per cent; at 200 p.p.m., 26 per cent; and at 400 p.p.m., only 12 per cent had apertures that large. In Fig. 1, $\left[\mathrm{CO}_{2}\right]_{\text {int }}$ varied from 8 to 240 p.p.m. as $\left[\mathrm{CO}_{2}\right]_{a}$ changed from 8 to 400 p.p.m.

Thus the concentration of carbon dioxide inside leaves is determined by the concentration difference and a series of resistances in the pathway from the atmosphere to the point of enzymatic fixation. Since both concentrations and resistances at different points in the pathway change, it is unrealistic to speak of a single concentration of carbon dioxide inside a leaf during photosynthesis, except under carefully specified conditions. In a steady-state, however, the concentration at the internal cell surfaces can be determined experimentally by a simultaneous measurement of photosynthesis and transpiration; or in the special case, when photosynthesis ceases because of low concentration of carbon dioxide, the concentration inside and outside the leaf will be the same.

DALE N. Moss

STEPHEN L. RAwLins

Connecticut Agricultural Experiment Station,

New Haven 4, Conn.

Gabrielsen, E. K., Nature, 163, 359 (1949).

I Heath, O. V. S., Nature, 184, 822 (1950).

${ }^{3}$ Gaastra, P., Med. Landbouwhgeschool Wageningen, 59 (1959).

4 Zelitch, I., Proc. U.S. Nat. Acad. Sci., 47, 423 (1961).

${ }_{3}$ Rawlins, S. L., and Moss, D. N., Agron. J, , 54, 181 (1962).

\section{Niacin Content of Coffee}

IN a recent communication ${ }^{1}$ A. Carvalho quoted some results of determinations of niacin in samples of coffee beans, which indicated variations in niacin content according to whether the coffee was grown with or without shade, and according to whether the 'cherries' wero sundried or de-pulped before drying.

These results, which vary from 0.160 to $0.400 \mathrm{mg} / \mathrm{g}$, are of the same order as the previously published values for roasted coffee ${ }^{2-5}$, and Carvalho has since informed me that they were in fact made after the samples had been roasted in a small electric roaster, to an intensity a little less than that of a type called Italian roast (namely, a high roast). Due to an omission this point was not made clear in his letter.

The production of nicotinic acid (namely, niacin) by the decomposition of trigonelline during the roasting of cuffee has been demonstrated ${ }^{2}$, the nicotinic acid content thereby increasing to up to 10 times the amount present in the raw beans. The effects of roasting conditions on niacin content of rossted coffee therefore far outweigh variations in niacin content of the raw beans, and the trigonelline content of the raw beans appears to be a deciding factor. It would therefore be interesting to know of the effects of growing and processing conditions on the trigonelline content of coffee beans.

Similar considerations might also apply to the production of pyridine (one of the constituents of coffee aroma), which also is formed by the decomposition of trigonelline during roasting ${ }^{6}$. The effects of growing and processing conditions on trigonelline content would be expected to have a bearing on flavour differences in roasted coffee.

Lyons Laboratories,

149 Hammersmith Road, London, W.14.

${ }^{1}$ Carvalho, A., Nature, 194, 1096 (1962).

${ }^{2}$ Hughes, E. B., and Smith, R. F., J. Soc. Chem. Indust., 65, 284 (1946) ${ }^{3}$ Teply, L. J., and Prier, R. F., Agric. and Food Chem., 5, 375 (1957).

'Bressani, R., and Navarreti, D. A., Food Res., 24, 344 (1959).

-Adrian, J., and Navellier, P., Café, Cacao, Thé, 5, 263 (1961).

- Hughes, E. B., and Smith, R. F., J. Soc. Chem. Indust., 68, 322 (1949).

\section{Fluorescent Lighting in Biological Research}

Is view of the prevalent use of fluorescent lighting in many types of biological research (for example, refs. 1 and 2 ), it is felt that the following observations may be of general interest.

Fluorescent tubes contain mercury vapour; the shortwave-length discharge induces a visible radiation from the phosphor coating of the tube walls. During research on another topic ${ }^{3}$, we observed emission from a typical daylight tube at 313,334 and $366 \mathrm{~m} \mu$ as well as in the visible spectrum. It was further shown that the glass of these tubes, $1 \mathrm{~mm}$ in thickness, transmitted over 50 per cent of the incident radiation at $310 \mathrm{~m} \mu$.

It has been shown that ultra-violet of $313 \mathrm{~m} \mu$ is mutagenic in Drosophila ${ }^{4}$ and it is generally known that light of this wave-length causes damage to tissue: while the ultraviolet incident on a surface more than $1 \mathrm{~m}$ from a 40 -W tube is far less than that from summer noon sunlight, it is worth noting that it is common to place the fluorescent. tube inside the cage or incubator and to leave it running continuously. This may seriously affect experimental results.

Most of the tubes also radiate strongly at 405 and $436 \mathrm{~m} \mu$. and while this radiation may not be dangerous to living material, it may accelerate degradation and bleaching of various of the more labile animal pigments; this may be of significance when it is considered that the radiation from most types of daylight fluorescent tubes is at least five 